\title{
Does Veterinary Science have a future in Australia?
}

\author{
JAL Maxwell* \\ Katanning Regional Veterinary Hospital, Australia \\ *Corresponding author: JAL Maxwell, Katanning Regional Veterinary Hospital, Katanning, 6317, Western Australia \\ To Cite This Article: JAL Maxwell. Does Veterinary Science have a future in Australia?. Am J Biomed Sci \& Res. 2019 - 4(2). AJBSR.MS.ID.000761. \\ DOI: $10.34297 / A J B S R .2019 .04 .000761$
}

Received: July 11, 2019 | Published: July 18, 2019

\section{Commentary}

In 2018, an Australian veterinary scientist asked the question, "Does Veterinary Science have a future in Australia [1]? The discipline of veterinary science has a relatively short history in Australia, and it was not until the 20th century that university veterinary education began. Four university veterinary schools were established in the 20th century $(1909,1910,1936$ and 1974), and during the 21st century, three new schools were added (2005, 2006 and 2008). Today, Australia has more veterinary schools per capita than any other western nation. Australia's veterinarians serve in private practice, government, academia and industry. Initially, veterinary scientists devoted their expertise to servicing economic livestock and this justified their utility to Australia's economy. However, today, approximately $90 \%$ function in private practice, with the majority providing a dog and cat GP service in urban and major regional centres, so the author askes the question, do we need the veterinary professions at all?

Historically, Great Britain established a penal colony on the east coast of Terra Australis in 1788, but it was not until 1901, that the Commonwealth of Australia was proclaimed. Prior to this, there was little need for veterinary scientists.

Australia's veterinary literature documents that the first veterinary practice was established in Sydney in 1841. As Australia developed an agricultural economy during the second half of the 19th century, the demand for veterinary scientists increased. During the first half of the 20th century, graduates from Australia's veterinary schools worked in institutions, such as government, academia and industry predominated, with private practitioners occupying a minor role. During the second half of that century, the situation reversed with the majority entering private practice and this coincided with the decline in the significance of livestock productivity in Australia's economy. Initially all livestock were imported, and Australia experienced animal diseases brought into the country and the need for quarantine became self-evident. State quarantine laws were put in place from 1871 and these were incorporated into the Commonwealth Government's Quarantine Act of 1908.

Numerous reviews of Australia's livestock quarantine took place during the 20th century, all recommending changes and in
2015, the Biosecurity Act was legislated. One review, however, stated that there was no evidence that quarantine actually worked, so, the question arose, is the reason that exotic livestock diseases that have entered Australia failed to gain a foothold, due to the quarantine vigilance in place or chance?

Australia's first veterinary teaching facility was established in 1888 by William Tyson Kendall in Melbourne. In 1909, this school was incorporated into Australia's first University veterinary school at the University of Melbourne. Others followed; 1910 (University of Sydney); 1936 (University of Queensland); 1974 (Murdoch University); 2005 (Charles Sturt University); 2006 (James Cook University); and, in 2008 (University of Adelaide).

A variety of opinions were voiced as to what direction veterinary education should take in Australia. Initially, veterinarians were seen to have a role in rural Australia servicing economic livestock. However, that changed to producing dog and cat GPs and this led to widespread dissatisfaction with the quality of veterinary education itself. as well as to the quality of graduating students. In a recent doctoral thesis, the same author examined three aspects of Veterinary Science in Australia, namely, services provided, quarantine and education [2]. An online survey questionnaire was used to assess the current status of veterinary services in Australia. The survey revealed the following results: $64 \%$ of respondents were female; $62 \%$ were raised in an urban environment; $26 \%$ were born overseas; $58 \%$ worked full-time; $85 \%$ worked in clinical practice; only 9\% providing a service "on-the-farm"; $6 \%$ were dissatisfied with their education, $16 \%$ with the work they carried out; $41 \%$ with the income they received and $19 \%$ with the status they achieved; 53\% suffered an injury or illness, which impaired their ability or led to retirement from the profession.

Oral history interviews were conducted with eight quarantine personnel and although they all agreed quarantine was necessary, there was concern for the current status of quarantine; some declaring it totally unsatisfactory with others stating that significant changes needed to be made. The consensus reached was that Australia was simply waiting for the next exotic disease incursion to occur. Seventeen past and present Dean and Heads of Schools were interviewed regarding the status of current veterinary education. 
Some cited the dramatic change from predominantly male to female students as the major change, whilst others cited the change from concern with economic livestock to almost exclusive interest in dogs and cats. In addition, differences were expressed regarding the change to the DVM degree. In the discussion, the author stated that veterinary education has been available in Australia for more than 100 years. During the first half of this period, veterinary graduates preferred to enter institutional service, especially government service, but that trend reversed during the second half with the majority entering private practice.

The Commonwealth Government reforms of the 1980s revolutionised university education in Australia. As a result, the output of veterinary science graduates represented only $0.2 \%$ of the total output of university graduates, and it is possible that the veterinary role could be accomplished by a science graduate with a background in biology. This may already be happening as veterinary science is no longer taught in separate veterinary schools but is now being taught within Science Faculties at Australia's universities. As the majority of today's veterinary graduates have turned their back on a career with livestock, preferring to provide a dog and cat GP service, is there justification for a veterinary science course at all? Similarly, government veterinary services including quarantine as well as university education could readily be undertaken by others with science qualification.

The author concluded that university education in Veterinary Science represents a relatively insignificant proportion of Australia's higher education output. The veterinary roles in practice, government, academia and industry could be accomplished by others with a scientific education. The author considers this a possibility according to the available literature and the results from his research. Others may disagree, but they will need to provide substantive evidence to support their opinions.

\section{References}

1. Maxwell JAL (2018a) Does Veterinary Science have a future in Australia? Insights in Veterinary Science 2: 018-126.

2. Maxwell JAL (2018b) Australia's Veterinarians and the Frawley Review of 2002. Murdoch University Veterinary Faculty. DVMSc Thesis 1: 204. 